\title{
Faktor Dominan Penyebab Remaja Melihat Video Porno di SMK PGRI 3 Tanggul
}

\author{
Jember Tahun 2017
}

\author{
Yunita Miftahul Masita \\ D-III Kebidanan, Akademi Kebidanan Bina Husada Jember \\ Email: masita.miftahul@yahoo.com
}

\begin{abstract}
Abstrak
Masa remaja merupakan masa yang rentan terhadap permasalahan kesehatan reproduksi. Rasa penasaran sangat besar pada mas ini, sehingga memicu remaja untuk mengetahui dan mencoba hal baru. Salah satu penyebab perilaku seksual beresiko pada remaja pada era digital ini adalah mudahnya mengakses video porno. Efek video porno pada remaja berdampak serius, kerena bisa berdampak pada kesehatan reproduksi seperti penyakit menular seksual, kehamilan tidak dinginkan,HIV-AIDS serta permasalah psikis pada remaja itu sendiri. Desain penelitian yang digunakan adalah deskriptif, teknik pengambilan sampelnya total sampling dan didapatkan 120 responden. Dimana peniliti ingin mengetahui faktor dominan yang menyebabkan remaja melihat video porno. Hasil penelitian menunjukkan bahwa dari responden yang melihat video porno sebanyak 120 responden.Sebanyak $40 \%$ memilih rasa penasaran,pergaulan dan lingkungan sebanyak $25,8 \%$, rasa ketagihan sebanyak $14,1 \%$, teman masturbasi sebanyak $11,7 \%$. Saran yang diberikan pada berbagai pihak agar lebih meningkatkan pemberian informasi secara professional, tepat sasaran dan meningkatkan upaya preventif melalui kerja sama tingkat sekolah.
\end{abstract}

Kata Kunci : Video Porno, Remaja

\begin{abstract}
Teenager is an population that easy to influence with the problem of reproduction system. In the time, there is an big wanted to try and know something new. Porn video is a good place that can be influence by the teenager to act an risk sexuality activity not only that the accesses to act get that porn video is really easy. Porn Video and the effect to the teenager is a big risk because can be effected to teenager. For example like unwanted pregnancy, infection sexsual disease, and HIV AIDS and can be effected to psicologise of teenager. Research design that use is descriptive the technic to get a data use total sample and get 120 respondent where is researcher want to know the dominant factor that causes the teenager to see porn video Result of the reserche prove that from the respondent is about 120 respondent.40 \% choose corious, $28 \%$ around of the teenager condition, $14,1 \%$ fell to see like addicted,11,7\% porn to do masturbation activity. To the people insude of it, have ti increase a good information with the right way and right place, and professional, increase the preventive act in work play school degree.
\end{abstract}

Keywords : Porn video, Teenager

\section{Pendahuluan}

Masa remaja atau masa adolensi adalah suatu fase perkembangan yang dinamis dalam kehidupan seorang individu.Masa ini merupakan periode transisi dari masa anak ke masa dewasa yang ditandai dengan percepatan perkembangan fisik, mental, emosional dan sosial dan berlangsung pada dekade kedua masa kehidupan.Buku-buku pediatric pada umumnya mendefinisikan remaja apabila telah mencapai umur 10-18 tahun untuk anak perempuan dan 12-20 tahun untuk anak laki-laki (Pardede, 2002).

Data yang ditemukan oleh National Research Council pada tahun 2002, menunjukkan bahwa 20-30 persen anak berusia 8-17 tahun mengakses situs porno. Sedangkan hasil survei dari Indonesia tak jauh berbeda, bahkan lebih parah. Hasil penelitian Yayasan Kita dan Buah Hati tahun 2005 di Jabodetabek, menunjukkan bahwa 80 persen anak usia 9-12 telah mengakses materi pornografi dari media, terutama internet.

Penelitian yang dilakukan oleh Dr Gina M.
Wingood dan tim di Univesitas Emory Grorgia A.S , mendapati bahwa dari 522 gadis dengan 14 - 18 tahun sebanyak 30\% pernah mengakses dan melihat video porno selama 3 bulan terkahir. Menurut Wingwood prosemeununtase sebanyak $30 \%$, menunjukkan prosentase yang memprihatinkan. Riset ini tidak memastikan dimana para remaja tersebut mengakses video porno tersebut. Tetapi menurut Dr Wingwood, hal ini sudah menjadi peringatan bagi para orang tua. Walaupu terdapat larangan untuk mengakses video tersebut, para remaja di era digital ini dapat dengan mudah mendapatkan video tersebut. Hal yang mengkhawatirkan ialah pengaruh perilaku seksual remaja dalam kehidupan yang nyata (Eddy, 2009).

Hasil survey dari Komanas Perlindungan Anak, tercatat sekitar 97\% remaja setingkat SMP dan SMA pernah menonton film porno, angka ini merupakan angka yang mengkhwatirkan untuk perilaku remaja kita. (Edy os hiariej, 2016). Perkembangan elektronik diera digital ini membuat media baik 
cetak maupun elektronik banyak dijadikan sorotan utama. Hal ini mau tidak mau menjadi salah satu penyebab menurunya moral umat manusia terutama remaja. Banyaknya tanyangan yang berbau pornografi, merupakan salah satu pencetus meningkatnya keserasan seksual saat ini.

Semakin canggihnya teknologi masa kini, menjadi salah satu akses masuknya hiburan dan tayangan yang berbau pornografi, tanpa ada sensor. Menurut penelitian terbaru, alur cerita film berbau pornografi ini, kerap kali memperlihatkan bahwa jika seseorang melakukan hubungan sex, seolah olah tidak menyebabkan masalah serius sama sekali. Film bergenre pornografi tersebut sangat berpengaruh terhadap berilaku sex beresiko pada remaja. Permasalahan yang selama ini banyak menjadi sorotan adalah keprihatinan terhadap kekerasan dan dampak perkembangan pada anak remaja. Sebenanrnya hal lebih perlu lebih diperhatikan adalah kemungkinan pengaruh buruk dari substansi film yang berbau unsur seksual tersebut. Penelitin yang dilaukan oleh Dr Wingood, perilaku perilaku seksual remaja lebih mudah terpengaruh, karena pada kelompok usia remaja. Besar kemungkinan akan meniru apa yang mereka lihat dalam film pornografi tersebut. (Eddy, 2009). Sebenarnya, fenomena video porno bukanlah hal baru di tanah air. Sejak beberapa tahun silam, video porno baik yang sengaja direkam pelaku maupun yang direkam secara sembunyi-sembunyi oleh pihak lain merebak di Indonesia.Padahal di Indonesia terdapat hukum yang melanggar tentang pornografi dan menjelaskan batasan tentang pornografi yaitu UU tentang pornografi.Tetapi UU tersebut tidak berjalan seperti yang diharapkan. Fenomena seperti ini banyak terjadi dimanamana termasuk di Tanggul kab.jember karena pada dasarnya secara umum remaja mengalami proses perkembangan yang sama. Mereka mengalami pertumbuhan fisik yang cepat, ketertarikan terhadap lawan jenis, dan memiliki rasa penasaran besar terhadap masalah seksual. Hal wajar yang terjadi pada hampir semua remaja. Namun sayangnya, masih banyak remaja yang tidak mendapatkan informasi masalah kesehatan reproduksi secara benar untuk mendampingi mereka dalam proses perkembangannya sehingga mereka seringkali tidak memahami resiko dari perilaku atau perbuatanya.

Berdasarkan studi pendahuluan di SMK PGRI 3 Tanggul dari 50 siswa diketahui 30 siswa yang pernah menonton video porno mereka mendapatkan video tersebut melalui internet, sebab itu peniliti tertarik untuk mengetahui faktor dominan penyebab remaja untuk melihat totonan pornogarfi. Oleh karena itu, progam kesehatan reproduksi remaja agar lebih memperhatikan upaya pencegahan perilaku seksual beresiko pada remaja, yang dilakukan melalui kerjasama ditingkat sekolah. Hal yang bisa kita lakukan adalah pemberian informasi secara rutin kepada siswa tentang informasi masalah kesehatan reporduksi, pentingnya pendidikan seks, pentinya peran orang tua dalam menciptakan komunikasi yang sehat pada anak dan juga perku adanya aturan yang ketat dai pemerintah setempat, yang ditujukan pada wanet ( warung internet) untuk memblokir situs porno yang mudah diakses oleh remaja.

\section{Metode Penelitian}

Berdasarkan jenis permasalahannya, penelitian ini menggunakan metode deskriptif dimana peneliti berusaha meneliti faktor dominan penyebab remaja melihat video porno di SMK PGRI 3 Tanggul-Jember.Pendekatan yang digunakan peneliti adalah cross sectional, dimana peneliti menggunakan satu kali pengumpulan data pada suatu saat. Adapun populasi dalam penelitian ini adalah siswa kelas X,XI di SMK PGRI 3 Tanggul yang berjumlah 120 siswa. Sampel pada penelituan ini adalah semua siswa SMK PGRI 3 Tanggul yang pernah melihat video porno.

Pada penelitian ini, pengambilan sampel dilakukan dengan total sampling. Pemilihan sampel dengan cara ini merupakan jenis probabilitas yang paling sederhana yaitu dengan menggunakan seluruh sampel penelitian. (Nursalam, 2008). Variabel penelitian pada penelitian ini adalah faktor dominan penyebab remaja melihat video porno di SMK PGRI 3 Tanggul-jember. Lokasi: SMK PGRI 3 Tanggul -Jember ,Waktu : 8 Juni 2017. Pada penelitian ini merupakan analisis deskriptif, yaitu prosedur pengolahan data dengan meringkas dan menggambarkan data secara ilmiah dalam bentuk tabel atau grafik.

$$
\begin{aligned}
& P=\times 100 \% \\
& \text { Keterangan : } \\
& P \text { : Angka prosentase } \\
& X: \text { Jumlah pertanyaan/jawaban yang dipilih } \\
& Y \text { : Jumlah seluruh pertanyaan }
\end{aligned}
$$

\section{Hasil Dan Pembahasan}

Hasil

Dalam riset ini, metode yang digunakan untuk mengumpulkan data yaitu cross sectional, dimana peneliti menggunakan satu kali pengumpulan data pada suatu saat. Tekhnik sampling yang digunakan adalah total sampling. Jumlah seluruh responden yaitu sebanyak 120 siswa. 
Tabel 1 Karakteristik Responden Menurut Jenis Kelamin.

Sumber Data: Data Primer

Berdasarkan tabel diatas dapat dijelaskan bahwa responden $64 \%$ adalah laki-laki dan perempuan $40 \%$.

Tabel 2.Karakteristik Responden Menurut Umur.

\begin{tabular}{lll}
\hline Kategori & Jumlah & Persen \\
\hline 15 tahun & 34 orang & $28.3 \%$ \\
16 tahun & 45 orang & $37.5 \%$ \\
17 tahun & 41 orang & $34.2 \%$ \\
\hline Jumlah & 120 orang & $100 \%$ \\
\hline
\end{tabular}

Sumber Data: Data Primer

Berdasarkan data di atas bahwa dapat di jelaskan bahwa usia responden yang berumur 16 tahun sebanyak 45 orang sebesar $37,5 \%$.

Data Khusus

Tabel distribusi frekuensi faktor rasapenasaran sebagai penyebab remaja melihat video porno di SMK PGRI 3 TANGGUL Kabupaten Jember tahun 2017

\begin{tabular}{lll}
\hline Kategori & Jumlah & Persen \\
\hline $\begin{array}{l}\text { Penasaran } \\
\begin{array}{l}\text { Tidak } \\
\text { penasaran }\end{array}\end{array}$ & 48 orang & $40 \%$ \\
\hline Jumlah & 120 orang & $60 \%$ \\
\hline
\end{tabular}

Sumber data: diolah oleh peneliti

Dari data diatas dapat dijelaskan bahwa Rasa Penasaran sebagai faktor penyebab remaja melihat video porno di SMK PGRI 3 TANGGUL sebanyak $40 \%$.

Pergaulan dan lingkungan sebagai faktor penyebab remaja melihat video porno di SMK PGRI 3 TANGGUL. Tabel 4.4 Tabel disrtibusi frekuensi faktor pergaulan dan lingkungan sebagai penyebab remaja melihat video porno di SMK PGRI 3 TANGGUL

\begin{tabular}{lll}
\hline Kategori & Jumlah & Persen \\
\hline $\begin{array}{l}\text { Pergaulan dan } \\
\text { lingkungan }\end{array}$ & 31 orang & $25.8 \%$ \\
$\begin{array}{l}\text { Bukan pergaulan } \\
\text { dan lingkungan }\end{array}$ & 89 orang & $74.2 \%$ \\
\hline Jumlah & 120 orang & $100 \%$ \\
\hline
\end{tabular}

Sumber data: diolah oleh peneliti

Dari tabel diatas dapat dijelaskan bahwa pergaulan dan lingkungan sebagai faktor penyebab remaja melihat video porno di SMK PGRI 3 TANGGUL adalah sebesar 25,8 \%.

Rasa ketagihan sebagai faktor penyebab remaja melihat video porno di SMK PGRI 3 TANGGUL tahun 2017.

Tabel 5 Tabel distribusi frekuensi rasa ketagihan sebagai faktor penyebab remaja melihat video porno di SMK PGRI 3 TANGGUL 2017.

\begin{tabular}{lll}
\hline Kategori & Jumlah & Persen \\
\hline Ketagihan & 17 orang & $14.1 \%$ \\
Bukan ketagihan & 119 orang & $85.1 \%$ \\
\hline Jumlah & 120 orang & $100 \%$ \\
\hline
\end{tabular}

Sumber data: diolah oleh peneliti

Dari tabel diatas dapat dijelaskan bahwa rasa ketagihan sebagai faktor penyebab remaja melihat video porno di SMK PGRI 3 TANGGUL sebanyak $14,1 \%$. Video porno dijadikan sebagai teman untuk masturbasi sebagai faktor penyebab remaja melihat video porno di SMK PGRI 3 TANGGUL 2017

Tabel 6. Tabel distribusi frekuensi video porno dijadikan sebagai teman untuk masturbasi sebagai faktor penyebab remaja melihat video porno di SMK PGRI 3 TANGGUL 2011.

\begin{tabular}{|c|c|c|}
\hline Kategori & Jumlah & Persen \\
\hline Teman masturbasi & 14 orang & $11.7 \%$ \\
\hline $\begin{array}{l}\text { Bukan sebagai } \\
\text { teman masturbasi }\end{array}$ & 106 orang & $88.3 \%$ \\
\hline Jumlah & 120 orang & $100 \%$ \\
\hline
\end{tabular}

Dari tabel diatas dapat dijelaskan bahwa video porno dijadikan sebagai teman masturbasi sebagai penyebab remaja melihat video porno di SMK PGRI 3 TANGGUL sebanyak 11,7\%.

Analisa Data

Dari Penelitian yang dilakukan didapatkan hasil sebagai berikut:

Tabel 4.7 Analisa Data

\begin{tabular}{|c|c|c|}
\hline No & $\begin{array}{ll}\text { Faktor } & \text { yang } \\
\text { mempengaruhi }\end{array}$ & $\begin{array}{l}\text { Hasil } \\
\text { persenta } \\
\text { se }\end{array}$ \\
\hline 1 & Faktor penasaran & $40 \%$ \\
\hline 2 & $\begin{array}{l}\text { Faktor lingkungan dan } \\
\text { pergaulan }\end{array}$ & $25.8 \%$ \\
\hline 3 & Faktor ketagihan & $14.1 \%$ \\
\hline 4 & $\begin{array}{l}\text { Faktor sebagai teman } \\
\text { untuk masturbasi }\end{array}$ & $11.7 \%$ \\
\hline
\end{tabular}

Penasaran adalah perasaan ingin mengetahui dan mendapatkan sesuatu. Seperti yang kita ketahui remaja memiliki mental yang cenderung labil. Mereka bisa melakukan apa saja, demi menjawab rasa penasaran mereka tanpa memikirkan dan mempertimbangkan akibatnya. Menurut Social Learning Theory dapat dijelaskan bahwa pornografi sangat mudah mempengaruhi hasrat seksual remaja. Para remaja tersebut mempelajari unsur seksualitas mulai dari mekanisme perilaku seksual sampai tempat dimana perilaku itu bisa terjadi,. Mereka mendapatkan hal tersebut dari hasil observasi dari berbagai macam media, sehingga mereka memahami tentang seksualitas sesuai dengan persepsi mereka sendiri tanpa ada arahan yang benar. Fenomena ini di perkuat dengan penelitian yang dilakukan di SMK PGRI 3 TANGGUL sebanyak $40 \%$ responden memilih rasa penasaran sebagai penyebab mereka lihat video porno.Faktor inilah yang merupakan faktor terbesar yang dipilih oleh responden.Mereka menganggap video porno menjawab rasa penasaran mereka terhadap seks itu sendiri. Ketidaktahuan mereka tentang pendidikan seks itu sendiri menjadi salah satu pemicu mengapa mereka melihat video itu tersebut,bahkan mereka rela meluangkan sebagian waktunya untuk mengunduh video 
tersebut di internet.

Menurut Wibowo (2004) bahwasanya media elektronik berkontribusi cukup besar dalam persepsi seksual remaja, karena infromasi tersebut memberikan pengetahuan dan wawasan terhadap nilai dari negara asal informasi tersebut didapatkan. Bellak (dalam Fuhrmann, 1990) secara khusus membahas pengaruh tekanan media terhadap perkembangan remaja. Menurutnya, remaja masa kini dihadapkan pada lingkungan dimana segala sesuatu berubah sangat cepat. Mereka dibanjiri oleh informasi yang terlalu banyak dan terlalu cepat untuk diserap dan dimengerti. Semuanya terus bertumpuk hingga mencapai apa yang disebut information overload. (Hadiwidjojo, 2010).

Ketagihan adalah hasrat atau keinginan terhadap sesuatu karena sudah menjadi kebiasaan. Apabila seorang remaja melihat video tersebut maka rasa tersebut akan timbul lagi sampai mereka melihat video tersebut,dan hal itu tidak dapat di kendalikan. Seperti yang di jelaskan sebelumnya kondisi tersebut lebih jauh dapat menuju pada satu kecenderungan akan perilaku adiksi (ketagihan atau kecanduan) Dampak pornografi bagi banyak orang yaitu menyebabkan kecanduan dan sifat progresif. Pengenalan pornografi pada usia dini berdampak pada semakin besarnya kecenderungan seseorang untuk melakukan tindakan seksual yang tidak semestinya, misalnya pemerkosaan. Seperti yang dijelaskan oleh terapi seks Dr louanne cole Weston yang juga seorang anggota panel mengatakan,ada beberapa hal mengapa seorang ketagihan melihat video porno yaitu untuk memuaskan fantasi, menghindari keintiman hubungan seks atau yang paling banyak menjadikan pornografi sebagai teman untuk masturbasi, faktor inilah yang kerap kali menjadikan video porno sebagai 'teman'untuk masturbasi.

\section{Kesimpulan Dan Saran}

Kesimpulan

Berdasarkan hasil penelitian dan pembahasan tentang faktor dominan penyebab remaja melihat video porno di SMK PGRI 3 TANGGUL tahun 2017, dapat diambil kesimpulan sebagai berikut:

Bahwa faktor dominan yang menyebabkan remaja melihat video porno adalah penasaran, dimana responden memilih faktor tersebut sebanyak $40 \%$, karena kelompok usia remaja memiliki karakteristik yang mudah terstimulasi dan dan memiliki rasa penasaran yang tinggi terhadap segala sesuatu hal, apalagi terhadap hal yang dianggap baru oleh mereka dan dianggap bisa menjawab rasa penasaran pada suatu hal.

Saran

Adapun saran yang dapat dituliskan untuk berbagai pihak adalah sebagai berikut:

1. Bagi peneliti selanjutnya diharapkan tidak mengulangi keterbatasan atau kekurangan yang peneliti lakukan selama penelitian dan selanjutnya mampu melakukan penelitian yang lebih baik.

2. Bagi masyarakat yaitu peningkatan pemberian informasi ditingkat sekolah, harus tepat sasaran yaitu berfokus pada perseta didik. Informasi yang diberikan mengenai kesehatan reproduksi pada remaja khusunya perilaku seksual beresiko pada remja. Pemberian informasi ini hendaknya disampaikan dengancara yang profesional dan tepat.

3. Adanya Program Kesehatan Reproduksi pada remaja, diharapkan lebih banyak menyentuh upaya preventif dan dilakukan kerjasama ditingakt sekolah. Seperti pemberian informasi secara rutin pada siswa tentang permasalahan seputar kesehatan reproduksi dan meningkatkan pengetahuan wali murid terhadap dampak negative pornografi pada perkembangan reproduksi pada remaja, sehingga para orang tua dapat secara cermat mengawasai penggunaan media elektronik sesuai dengan batas yang diperbolehkan bagi para buah hati mereka.

\section{Daftar Pustaka}

Arianto, (2008) Pornografi di Media Massa dan Pengaruhnya pada Remaja.http:-pornografidi-media-massa-dan-pengaruhnya-padaremaja.htm

Februana, N., (2009). Resiko film Porno Bagi Remaja. http://rumahbelajar psikologi.com.

Kristiono (2007). Mencegah Anak Dari Video Porno 28 Tips Untuk Orang tua http://BELAJAR-PSIKOLOGI.htm

Kristiono, (2004) Perangkat internet yang sehat dan aman.http:

Bahaya.Pornografi.Bagi.Anak..htp

Mark (2008).Ciri-ciri Video Pornografi http://www.sumbercerita.com

Notoatmodjo, S. (2005). Pendidikan dan Perilaku Kesehatan. Jakarta: Rineka CiptaSalemba Medika

Nursalam. (2008). Konsep dan Penerapan Metodologi penelitian Ilmu Keperawatan. Jakarta: Rineka Cipta 
Pardede,(2002).Tubuh Kembang Anak dan Remaja.Jakarta:Sagung Seto Soebagjo (2007). Paparan Pornografi

Soetjiningsih.(2004).Tumbuh Kembang Remaja dan Permasalahannya. Jakarta: CV. Sagung Seto

Stefy (2008) Faktor yang Mempengaruhi Efek Pornografi http://Pornografi.htm

Swetspe (2008). Banjir Video Porno Bikin ABG Candu Seks www.inilah.com.htm

Uno,B,Hamzah.(2008).Teori Motivasi dan Pengukuranya.Jakarta:PT Bumi Aksara.

Wibowo, S., (2010). Perkembangan dan Pertumbuhan Pada Masa Remaja. http: rosy46nelly.com 